\title{
The effects of changing the resolution of land-use modeling on simulations of land-use patterns and hydrology for a watershed land-use planning assessment in $\mathrm{Wu}-\mathrm{Tu}$, Taiwan
}

\author{
Yu-Pin Lin ${ }^{\mathrm{a}, *}$, Pei-Jung $\mathrm{Wu}^{\mathrm{a}}$, Nien-Ming Hong ${ }^{\mathrm{b}}$ \\ ${ }^{a}$ Department of Bioenvironmental Systems Engineering, National Taiwan University, No. 1, Sec. 4, Roosevelt Road, Taipei 106, Taiwan \\ ${ }^{\mathrm{b}}$ Department of Environmental Resources Management, The Overseas Chinese Institute of Technology, No. 100, Chiao Kwang Road, Taichung 407, Taiwan
}

\section{A R T I C L E I N F O}

\section{Article history:}

Received 10 May 2007

Received in revised form 1 April 2008

Accepted 9 April 2008

Available online 21 May 2008

\section{Keywords:}

Extent

Grain size

Landscape ecology

Spatial autocorrelation

\begin{abstract}
A B S T R A C T
The objective of this study was to analyze the planning strategy and observe the scaling effects on both simulated land-use patterns and hydrological components for the study watershed. The land-use modeling results revealed that altering grain sizes would have various impacts on the composition variables in logistic regressions of the land-use model used to simulate different land-use types with spatial characteristics. The landscape metrics showed that the effects of changing grain sizes on simulated land-use composition were significant when the grain size was increased to 2.5 times that of the finest grain in the watershed. Simulated hydrological components also changed significantly when the grain size of landuse modeling increased to 2.5 times that of the finest grain in the watershed. Moreover, in sub-watershed areas, the gradients of the spatial correlations of land-use patterns and hydrological components were in the reverse direction when the grain size was increased to twice that of the finest grain in the simulated period. The relations between grain size and both simulated hydrological components and land-use patterns present similar scale-relation functions.
\end{abstract}

Crown Copyright @ 2008 Published by Elsevier B.V. All rights reserved.

\section{Introduction}

The disciplines of landscape ecology and watershed hydrology deal with patterns and processes as well as their interactions and functional implications on a variety of scales (Turner, 2005; Sivapalan, 2005; Schröder, 2006). Thus, it is reasonable to study the interplay between ecological and hydrological patterns and processes and seek mutual opportunities to help both disciplines address their respective research questions (Schröder, 2006). Integrated land-use and hydrological simulation models can help decision-makers evaluate planning strategies for specific objectives or purposes, such as assessing the impact of future land-use scenarios on watershed hydrology by using landscape, ecological, and catchment hydrological approaches. Moreover, assessing and modeling the effects of land-use changes on hydrological processes is an important issue in the management of river basins (Eckhardt et al., 2003). In land-use modeling, scale influences the measurement and quantitative description of land-use patterns; thus, it can impact significantly on the behavior of model parameters used to

\footnotetext{
* Corresponding author. Tel.: +8862 33663464; fax: +886223686980.

E-mail addresses: yplin@ntu.edu.tw(Y.-P.Lin), r95622002@ntu.edu.tw(P.-J.Wu), hong@ocit.edu.tw (N.-M. Hong).
}

describe land-use change processes (Jenerette and Wu, 2001; Jantz and Goetz, 2005; Lin et al., 2007). Furthermore, the complexity of the relationships between land-use patterns and their spatial determinants has a scaling effect on land-use modeling results (Kok and Veldkamp, 2001). Although water is one of the most fundamental resource in any landscape (Leitão et al., 2006), the composition and configuration of the landscape or land-use patterns strongly influence the hydrological connectivity and control the catchment response (Schröder, 2006). When evaluating the impact of scale on land-use planning, the hydrological components should be taken into account. Hydrological models of a watershed's scale are usually used to quantify the impact of land-use changes on hydrological components (Haverkamp et al., 2005; Lin et al., 2007). In hydrological modeling, simulation of a land cover change modifies the input parameter values associated with the land cover, especially parts of a catchment area (Eckhardt et al., 2003). Therefore, the scale effects and scale selections used in land-use simulations to model hydrological components are critical to the analysis of landuse patterns and changes in hydrology when assessing watershed planning strategies.

Determining the resolution and extent of a watershed's land-use patterns is of fundamental importance for reducing the bias in landscape, land-use pattern (Farina, 2000), and hydrological studies. Scale selection must be based on the objective of the study (Turner 
et al., 2001). Moreover, specific objectives must be examined in the context of potential scale dependence in the model (Jantz and Goetz, 2005). However, simulation results based on the finest grain size of the data and the model's application may not always provide an inaccurate description of the hydrological characteristics of the given area (Farina, 2000; Bormann, 2006). For example, parameters and processes that are predictive on one scale are frequently unpredictive on another scale; thus, information is lost when spatial data is considered at coarser scales of resolution (Meentemeyer and Box, 1987; Turner, 1989). Moreover, the finest data may not always be available for a study watershed.

In the last decade, landscape metrics have been used increasingly to assess scale effects in ecology, remote sensing, geography, and land-use studies (O'Neill et al., 1996; Qi and Wu, 1996; Turner et al., 2001; Price et al., 2005; Wu, 2004; Lin et al., 2006, 2007). Variables that characterize landscape patterns, such as the number, area, and spatial patterns of different patch types, change when the scale (grain size and/or extent) is altered (Wiens, 1989; Wu et al., 2002). Landscape composition, configuration, and connectivity are primary descriptors of landscape patterns (Turner et al., 2001), and can be quantified using spatial landscape indices or metrics. Landscape metrics have proved effective in land-use planning and design because they can characterize the differences between the planned use and the design alternatives (Jongman, 1999; Leitão and Ahern, 2002; Corry and Nassauer, 2005; Lin et al., 2007).

The objective of this study was to assess a land-use conservation planning strategy and the effects of changing the grain size on watershed and sub-watershed extents and five spatial resolutions $(50 \mathrm{~m} \times 50 \mathrm{~m}, 75 \mathrm{~m} \times 75 \mathrm{~m}, 100 \mathrm{~m} \times 100 \mathrm{~m}, 125 \mathrm{~m} \times 125 \mathrm{~m}$, and $150 \mathrm{~m} \times 150 \mathrm{~m}$ ) of spatial driving factors. An empirical land-use change model was used to simulate land-use scenarios for landuse pattern analysis. Besides using landscape indices to describe landscape patterns of simulated land-use, a hydrological model was used to calculate the hydrological components, which reflected the scale effects on land-use changes, hydrological processes, and their relations with various grain sizes and extents in the $\mathrm{Wu}-\mathrm{Tu}$ watershed in Taiwan.

\section{Methods and materials}

In this study, the characteristics of land-use types with their driving factors were fit by logistic regression models for all land-use types to assess the dominant driving factors at various resolutions. Then, an empirical land-use change model with logistic regression analysis was used to simulate various land-use patterns using the dominant driving factors of land-use changes at various resolutions with the land-use planning strategy for the Wu-Tu watershed in Taiwan. Landscape metrics for the land-use planning strategy at the landscape level in the watershed and sub-watershed extents were calculated using the Patch Analyst landscape pattern analysis software package (Elkie et al., 1999), which is a extension of the ArcView geographic information system (GIS) software (Version 3.0a). Furthermore, simulated land-use patterns on various scales were input to a hydrological model to simulate hydrological components in the watershed and sub-watershed for the analysis of scaling effects on land-use associated with simulated hydrological components in the study watershed. Moreover, global Moran's I correlations of the landscape metrics and hydrological components of sub-watersheds were calculated to compare the effects of scale on the spatial relations of land-use patterns and hydrological components among the sub-watersheds. In this study, we did not discuss the grain sizes of the entire watershed because land-use demands (total area) of all land-use types are almost same for various grain sizes for the entire watershed. Hydrological outputs based on same total area of landuses were the same for various grain sizes. Therefore, the effects of

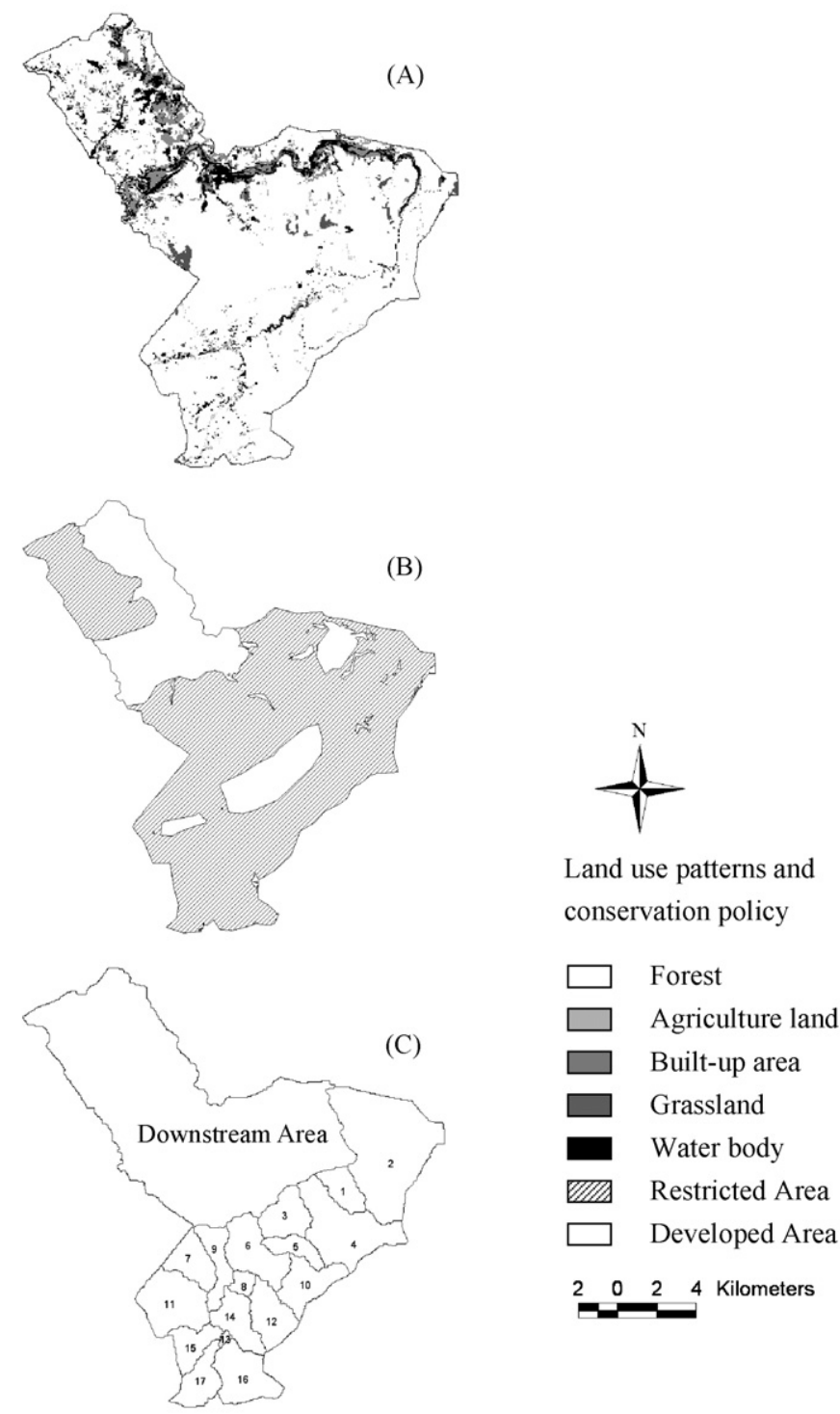

Fig. 1. (A) Land-use patterns in 1999, (B) the conservation policy, and (C) the 17 sub-watersheds of the upstream area of the $\mathrm{Wu}$-Tu watershed.

changing grain size on simulated land-use patterns and hydrology were discussed for the sub-watershed of the upstream watershed.

\subsection{Study area and data}

The Wu-Tu watershed is located east of the Taipei Basin in northern Taiwan (Fig. 1(A)). The area, mean elevation, and mean slope of the watershed are approximately $204.41 \mathrm{~km}^{2}, 242.00 \mathrm{~m}$, and $0.005^{\circ}$, respectively. The watershed has become extremely urbanized due to the growth of Taipei City and Keelung City (Lin et al., 2007). In recent years, the average annual population growth rate has been approximately $1.05 \%$ lower than that before 1997 . The proportions of agricultural land, forest, built-up land, grassland, and the water body in 1999 were $1 \%, 83 \%, 6 \%, 3 \%$, and $7 \%$, respectively (Fig. 1(A)).

Following land-use modeling by Lin et al. (2007), the driving factors in the Wu-Tu watershed were identified as demography, social economics, infrastructure, geomorphology, and soil-related variables. The variables were as follows: altitude ( $\mathrm{m})$, slope, distance from the river, soil erosion coefficient, soil drainage, distance 
from major roads, distance from a built-up area, distance from urban planning areas, and population density. Data for the landuse and driving factors was generated and digitized by the Soil and Water Conservation Bureau using 1:5000 aerial photographs taken in 1999. Grain sizes in the maps of land-use and driving factors were aggregated from $50 \mathrm{~m} \times 50 \mathrm{~m}$ to $75 \mathrm{~m} \times 75 \mathrm{~m}, 100 \mathrm{~m} \times 100 \mathrm{~m}$, $125 \mathrm{~m} \times 125 \mathrm{~m}$, and $150 \mathrm{~m} \times 150 \mathrm{~m}$ resolutions.

In this work, the conservation planning strategy, which included both an agricultural protection conversion area and a large protected area (Fig. 1(B)), was simulated for the study area based on land-use demand and conversion rules, with the land-use demand determined by an annual birth rate of $1.50 \%$. This large protected area is covered by a conservation plan that protects hillsides, water supply sources, and large forested areas, which are located primarily upstream of the watershed (Fig. 1). Built-up areas increased at an average rate of approximately $2 \%$ in every time step, while forest, agricultural land and grassland areas decreased at an average rate of approximately $0.14 \%, 1.47 \%$, and $0.87 \%$, respectively (Fig. 2 ).
It was assumed that the water body (stream) would be constant for land-use demands during the period 2000-2020. The 1995 agricultural land release policy of the Council of Agriculture stipulated two land-use conversion rules (free conversion and agricultural protection conversion) (Lin et al., 2007). Free conversion allows agricultural land to be converted into built-up areas or forested land, whereas agricultural protection conversion does not. In this study, agricultural protection conversion areas and large restricted areas (Fig. 1(B)) were taken into account, especially those in the upstream watershed.

\subsection{Empirical land-use change model}

An empirical land-use model, called the conversion of land-use and its effects (CLUE-s) model, was employed to simulate future land-use patterns in the study area. Land-use change modeling must be performed and annual land-use demand must be determined before implementing a land-use allocation procedure. Next,
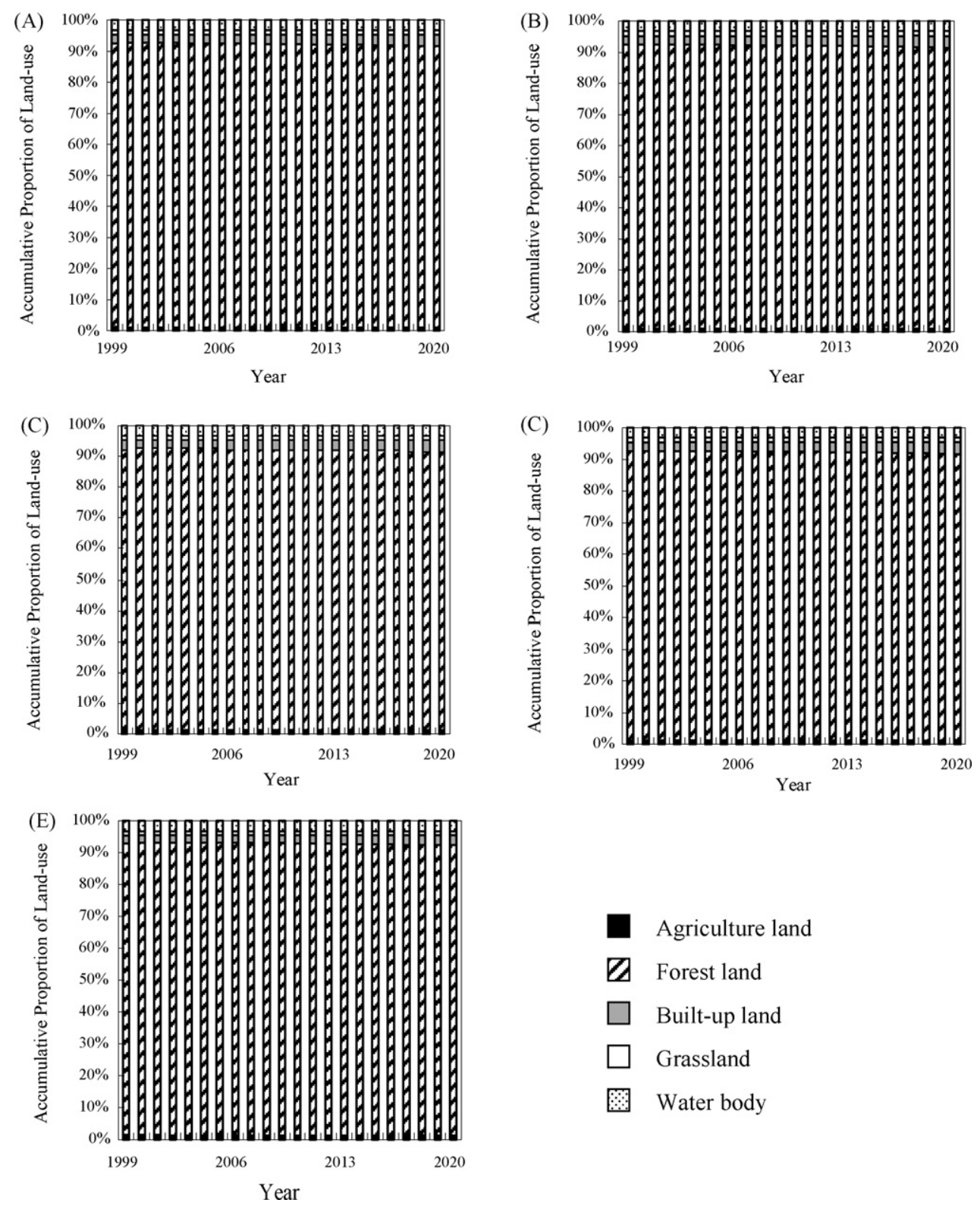

Fig. 2. Simulated land-use changes with different grain sizes: (A) $50 \mathrm{~m} \times 50 \mathrm{~m}$, (B) $75 \mathrm{~m} \times 75 \mathrm{~m}$, (C) $100 \mathrm{~m} \times 100 \mathrm{~m}$, (D) $125 \mathrm{~m} \times 125 \mathrm{~m}$, and (E) $150 \mathrm{~m} \times 150 \mathrm{~m}$. 
spatial policies and decision rules must be specified. The model allocates land-use changes by an iterative procedure that utilizes probability maps and decision rules combined with actual land-use maps and demand for different types of land-use (Lin et al., 2007). A preliminary allocation of iteration variables gives equal value to all land-use types by assigning each type a high total probability of land-use for the considered grill cell. The value of the iteration variable is increased for land-use types where the allocated area is smaller than the demand area. The iterative process continues until the aggregated cover of all grid cells is equal to land-use demands.

Probability maps for all land-use types are calculated with logistic regression models. The relationships between different types of land-use and the driving factors are then obtained using stepwise logistic regression as follows:

$\log \left(\frac{P_{i}}{1-P_{i}}\right)=\beta_{0}+\beta_{1} X_{1, i}+\beta_{2} X_{2, i}+\cdots+\beta_{n, X_{n, i}}$,

where $i$ is the $i$ th grid cell, $P_{i}$ is the probability of a land-use type occurring in a grid cell $i, X_{n, j}$ is the driving factor, $n$ is the number of driving factors, $\beta_{0}$ is the intercept of the regression model, and $\beta_{n}$ is the coefficient of each driving factor in the model. The relative operating characteristic (ROC) is applied to assess the goodnessof-fit of the model's logistic regressions. The ROC value is defined as the area under the curve linking the relationship between the proportion of true positives versus the proportion of false positives for an infinite number of cut-off values (Overmars and Verburg, 2005). In this study, forward stepwise logistic regression and ROC analysis were performed using the Statistical Package for the Social Sciences (SPSS) for Windows (SPSS Inc., Illinois, USA).

\subsection{Landscape metrics and global spatial autocorrelation}

The principal metrics of landscape composition are proportion abundance, richness, evenness, and diversity (McGarigal, 2002). The principal aspects of the configuration are patch size distribution, patch shape complexity, and core area (McGarigal, 2002). In this study, the following landscape configuration metrics were calculated using the Patch Analyst in the GIS ArcView software: the number of patches (NP), the mean patch size (MPS), the total edge (TE), the mean shape index (MSI), and landscape composition metrics, including Shannon's evenness index (SHEI) and Shannon's diversity index (SHDI) at the landscape level in the watershed and the sub-watershed:

$\mathrm{MPS}=\frac{A}{\mathrm{NP}}\left(\frac{1}{10,000}\right)$,

$\mathrm{MSI}=\frac{\sum_{i=1}^{m} \sum_{j=1}^{m}\left(\frac{0.25 p_{i j}}{\sqrt{a_{i j}}}\right)}{\mathrm{NP}}$,

$\mathrm{SHEI}=\frac{-\sum_{i=1}^{m}\left(P_{i} \ln P_{i}\right)}{\ln m}$,

SHDI $=-\sum_{i=1}^{m}\left(P_{i} \ln P_{i}\right)$,

where $A$ is the total landscape area $\left(\mathrm{m}^{2}\right)$, NP is the total number of patches in the landscape, $p_{i j}$ is the perimeter length $(\mathrm{m})$ of patch $i j, a_{i j}$ is the area $\left(\mathrm{m}^{2}\right)$ of patch $i j, P_{i}$ is proportion of the landscape occupied by patch type I, $m$ is the number of patch types in the landscape, and $n$ is the number of patches of each types in the landscape. The detail descriptions of landscape metrics could be found in the FRAGSTATS user's manual (McGarigal and Marks, 1995).

Spatial autocorrelation is a useful tool for describing the dependency of spatial patterns. First, spatial structures are described by so-called structure functions (Legendre, 1993; Lin et al., 2006). Moran's $I$, which ranges between -1 and +1 , is a well-known spatial autocorrelation method (Moran, 1950). The index, $I$, is calculated as follows:

$I=\frac{(1 / W) \sum_{h=1}^{n} \sum_{i=1}^{n} w_{h i}\left(y_{h}-\bar{y}\right)\left(y_{i}-\bar{y}\right)}{(1 / n) \sum_{i=1}^{n}\left(y_{i}-\bar{y}\right)^{2}}$,

where $y_{h}$ and $y_{i}$ denote the values of the observed variable at sites $h$ and $i$, respectively; and $w_{h i}$ denotes the weight of the variable. The weights, $w_{i j}$, are written in an $(n \times n)$ weight matrix $W$, which is the sum of the weights $w_{h i}$ for a given distance class (Legendre and Legendre, 1998). Global Moran's I is high and positive when a value is similar to adjacent values, and low when a value is dissimilar to adjacent values. The index is useful for assessing whether the dominant effects are caused by a reaction to external forces or by the interaction of neighboring sub-watersheds (Overmars et al., 2003). The values of global Moran's I for the simulated hydrology and landscape metrics were calculated to compare the spatial relations of the metrics and the hydrological components among various grain sizes for the sub-watershed area. As a result, the phenomenon of spatial autocorrelation of metrics and hydrological components could be tested.

\subsection{Hydrological model}

The generalized watershed loading functions (GWLF) model, which was developed by Haith and Shoemaker (1987), is a combined distributed/lumped parameter watershed model for simulating runoff, sediment, and nutrient loadings in watersheds whose source areas vary in size and usage. In the GWLF model, the water mass balance equation for an unsaturated zone is (Howarth et al., 1991; Tung, 2001; Lin et al., 2007):

$U_{t+1}=U_{t}+I_{t}-\mathrm{ET}_{t}-\mathrm{PC}_{t}$,

where $U_{t+1}(\mathrm{~cm})$ and $U_{t}(\mathrm{~cm})$ are the moisture content of the surface unsaturated soil zone in excess of the field capacities on days $t+1$ and $t$, respectively; $I_{t}(\mathrm{~cm})$ denotes the amount of water that infiltrates on day $t$; $\mathrm{ET}_{t}$ represents the evapotranspiration $(\mathrm{cm})$ on day $t$; and $\mathrm{PC}_{t}(\mathrm{~cm})$ is the amount of percolation into the deep saturated zone on day $t$.

The amount of infiltrated water, $I_{t}$, is the difference in infiltration between rainfall $\left(R_{t}\right)$ and surface runoff $\left(Q_{t}\right)$. Evapotranspiration is influenced by atmospheric conditions, water usage patterns, and the soil's moisture content. The relationship of these factors is defined as follows (Tung, 2001):

$\mathrm{ET}_{t}=\min \left[k_{s t} \times k_{c t} \times \mathrm{PET}_{t}, U_{t}+I_{t}\right]$

where $k_{s t}$ and $k_{c t}$ are the coefficients of soil moisture stress and land cover, respectively; and $\mathrm{PET}_{t}$ is the potential evapotranspiration calculated using Hamon's equation (Tung, 2001). In addition, percolation occurs when the moisture of the soil in an unsaturated zone exceeds the field capacity. It is calculated by

$\mathrm{PC}_{t}=\max \left[0, U_{t}+I_{t}-\mathrm{ET}_{t}-U^{*}\right]$,

where $U^{*}$ denotes the maximum soil water capacity $(\mathrm{cm})$.

The water balance equation for a shallow saturated zone is

$S_{t+1}=S_{t}+\mathrm{PC}_{t}-G_{t}-D_{t}$,

where $S_{t}(\mathrm{~cm})$ denotes the water content of a shallow groundwater aquifer at the beginning of day $t, D_{t}$ represents the deep seepage $(\mathrm{cm})$ during day $t$, and $G_{t}(\mathrm{~cm})$ is the groundwater discharge into streams/rivers. The movement of water from the saturated zone 
to streams/rivers $\left(G_{t}\right)$ is taken as a linear function of the moisture content of the saturated zone (Howarth et al., 1991):

$G_{t}=r S_{t}$

where $r$ is the regression coefficient.

We used stream flow data for a 10-year period (1993-2002) to verify the simulated stream flow modeled by the GWLF model, which used historical weather data and the following parameters: the regression coefficient, the evapotranspiration coefficient, and the curve number $(\mathrm{CN})$. Furthermore, the $R$ and $R^{2}$ values of the linear regression model with a slope of 0.977 of the monthly mean observed stream flows and the mean simulated stream flows during the 10 -year period were 1.0 and 0.99 , respectively. Both linear regression models were significant at the $p \leq 0.01$ level. In the hydrological modeling, the relationships between land-use change models and the hydrological model were included as the $\mathrm{CN}$ values of runoff generation and the cover coefficients of vegetation. For example, under this approach, if the land-use changes from forest to agriculture, then a higher $\mathrm{CN}$ value and a lower cover coefficient would be used. The results of such land-use change would be more surface runoff, less groundwater discharge, and less evapotranspiration.

\section{Results}

\subsection{Land-use change models in various grain sizes}

Table 1 presents the estimated coefficients and ROC values of forward stepwise logistic regression models for all land-use patterns (except water bodies) in the following five grain sizes: $50 \mathrm{~m} \times 50 \mathrm{~m}$, $75 \mathrm{~m} \times 75 \mathrm{~m}, 100 \mathrm{~m} \times 100 \mathrm{~m}, 125 \mathrm{~m} \times 125 \mathrm{~m}$, and $150 \mathrm{~m} \times 150 \mathrm{~m}$. The fitted logistic models were applied to predict the probabilities of all land-use types and measure the relationships between the probabilities and driving factors for various resolutions. The ROC values for the models were $0.73-1.00$ for all grain sizes. The driving factors, i.e., elevation (Dtm), population density (PopD), and the soil erosion coefficient (Soilk), did not affect the logistic regression model's ability to predict agricultural land-use when the grain size was $>100 \mathrm{~m} \times 100 \mathrm{~m}$. Note that the distance from main roads
(Droad) and urban planning areas (Dzone) was not included in the regression model when calculating the probability of agricultural land-use at grain size $125 \mathrm{~m} \times 125 \mathrm{~m}$. Furthermore, the coefficients of population density in regression models became negative for the probability of agricultural land when the grain size was increased beyond $50 \mathrm{~m} \times 50 \mathrm{~m}$. In the prediction of forested areas, the distance from roads and urban planning areas, and the distance to rivers (Driver), did not contribute to the logistic regression model when the grain size was $>125 \mathrm{~m} \times 125 \mathrm{~m}$. The number of driving factors declined from 4 to 1 (distance from built-up areas) in the logistic regression model for predicting built-up areas when the grain size was $>100 \mathrm{~m} \times 100 \mathrm{~m}$. Furthermore, soil drainage (Odr), the distance from urban planning areas and the distance to rivers did not contribute to logistic regression models for predicting grassland areas at grain sizes of $75 \mathrm{~m} \times 75 \mathrm{~m}, 100 \mathrm{~m} \times 100 \mathrm{~m}$, and $150 \mathrm{~m} \times 150 \mathrm{~m}$.

In this study, the effects of changing grain size of the entire watershed were not discussed because land-use demands of all land-use types are almost same for different grain sizes for the entire watershed. Moreover, the total area of each land-use type of upstream watershed has been changed by the land-use model. The results of simulated land-use of the upstream watershed during 1999-2020 are shown in Fig. 2. The area of agriculture lands increased with different grain sizes (Fig. 2(A)). The simulated landuse of forested areas, the main land-use type upstream of the watershed, had a minimum area value at grain size $100 \mathrm{~m} \times 100 \mathrm{~m}$ (Fig. 2(B)). The forested areas at grain sizes $50 \mathrm{~m} \times 50 \mathrm{~m}$ and $125 \mathrm{~m} \times 125 \mathrm{~m}$ were similar. Fig. 2(C) shows that the patterns of land-use change in built-up areas increased over the years and varied with grain sizes, which is a different trend to that of forest and agriculture land. Moreover, the area of built-up land increased over the years and had similar values at different grain sizes, except at grain size $150 \mathrm{~m} \times 150 \mathrm{~m}$. The changes in grassland, shown in Fig. 2(D), did not exhibit an obvious decreasing or increasing trend.

\subsection{Simulated land-use patterns for changing scales}

The landscape-level metric results show that increasing the grain size from $50 \mathrm{~m} \times 50 \mathrm{~m}$ to $150 \mathrm{~m} \times 150 \mathrm{~m}$ reduced the values of NP, TE and MSI for simulated land-use patterns during

Table 1

Logistics regression model for land-use types in different grid sizes

\begin{tabular}{|c|c|c|c|c|c|c|c|c|c|c|c|c|}
\hline \multirow[t]{2}{*}{ Grid size $(\mathrm{m})$} & \multirow[t]{2}{*}{ Land-use type } & \multicolumn{11}{|c|}{ Driving factors } \\
\hline & & Dtm & Slope & PopD & Droad & Driver & Dbuilt & Dzone & Odr & Soilk & $C$ & $\mathrm{ROC}$ \\
\hline \multirow[t]{4}{*}{50} & Agriculture & 0.0015 & -0.041 & 0.0002 & -0.0012 & - & -0.0019 & 0.0003 & - & 2.1461 & -3.1464 & 0.735 \\
\hline & Forest & 0.0016 & 0.0653 & -0.0001 & -0.0002 & 0.0001 & 0.0069 & - & - & 4.6479 & -1.4859 & 0.88 \\
\hline & Built-up & - & -0.0203 & $3.17 \mathrm{E}-05$ & - & - & -0.0627 & - & - & -1.8691 & 1.5537 & 0.983 \\
\hline & Grass & -0.0043 & -0.0278 & - & 0.0011 & -0.0002 & -0.0025 & $-9.34 \mathrm{E}-05$ & 0.4670 & - & -2.3934 & 0.757 \\
\hline \multirow[t]{4}{*}{75} & Agriculture & 0.0016 & -0.0316 & -0.0001 & -0.0015 & - & -0.0012 & -0.0003 & - & 2.1724 & -3.3421 & 0.730 \\
\hline & Forest & 0.0013 & 0.0588 & -0.0001 & -0.0002 & 0.0002 & 0.0065 & - & - & 4.8862 & -1.3567 & 0.874 \\
\hline & Built-up & - & -0.0149 & 0.0000 & - & - & -0.0483 & - & - & -2.3359 & 1.0928 & 0.973 \\
\hline & Grass & -0.0046 & -0.0278 & - & 0.0011 & -0.0003 & 0.0023 & -0.0001 & - & - & -1.8798 & 0.76 \\
\hline \multirow[t]{4}{*}{100} & Agriculture & - & -0.0504 & -0.0002 & -0.0012 & - & -0.0012 & -0.0003 & - & - & -2.7965 & 0.735 \\
\hline & Forest & 0.0015 & 0.0771 & -0.0001 & -0.0003 & 0.0001 & 0.0077 & - & - & 4.6894 & -1.6956 & 0.89 \\
\hline & Built-up & - & - & - & - & - & -0.6040 & - & - & - & 15.2120 & 1 \\
\hline & Grass & -0.0045 & -0.0325 & - & 0.0010 & -0.0002 & -0.0025 & - & - & - & -1.8998 & 0.761 \\
\hline \multirow[t]{4}{*}{125} & Agriculture & - & -0.0575 & -0.0002 & -0.0007 & - & -0.0023 & - & - & - & -2.5770 & 0.75 \\
\hline & Forest & 0.0019 & 0.0758 & -0.0001 & - & - & 0.0074 & - & - & 4.92002 & -1.7772 & 0.891 \\
\hline & Built-up & - & - & - & - & - & -0.6040 & - & - & - & 15.2152 & 1 \\
\hline & Grass & -0.0051 & -0.0190 & - & 0.0009 & -0.0003 & -0.0022 & - & - & - & -1.9366 & 0.756 \\
\hline \multirow[t]{4}{*}{150} & Agriculture & - & -0.0368 & -0.0002 & - & - & -0.0042 & - & -0.8850 & 3.4603 & -2.2829 & 0.761 \\
\hline & Forest & 0.0017 & 0.0676 & -0.0001 & - & - & 0.0078 & - & - & 4.0773 & -1.5624 & 0.888 \\
\hline & Built-up & - & - & - & - & - & -0.6045 & - & - & - & 15.1876 & 1 \\
\hline & Grass & -0.0056 & -0.0322 & - & 0.0011 & - & -0.0027 & - & - & - & -1.8431 & 0.773 \\
\hline
\end{tabular}

-: not significant and not included in model at 0.05 significant level. 

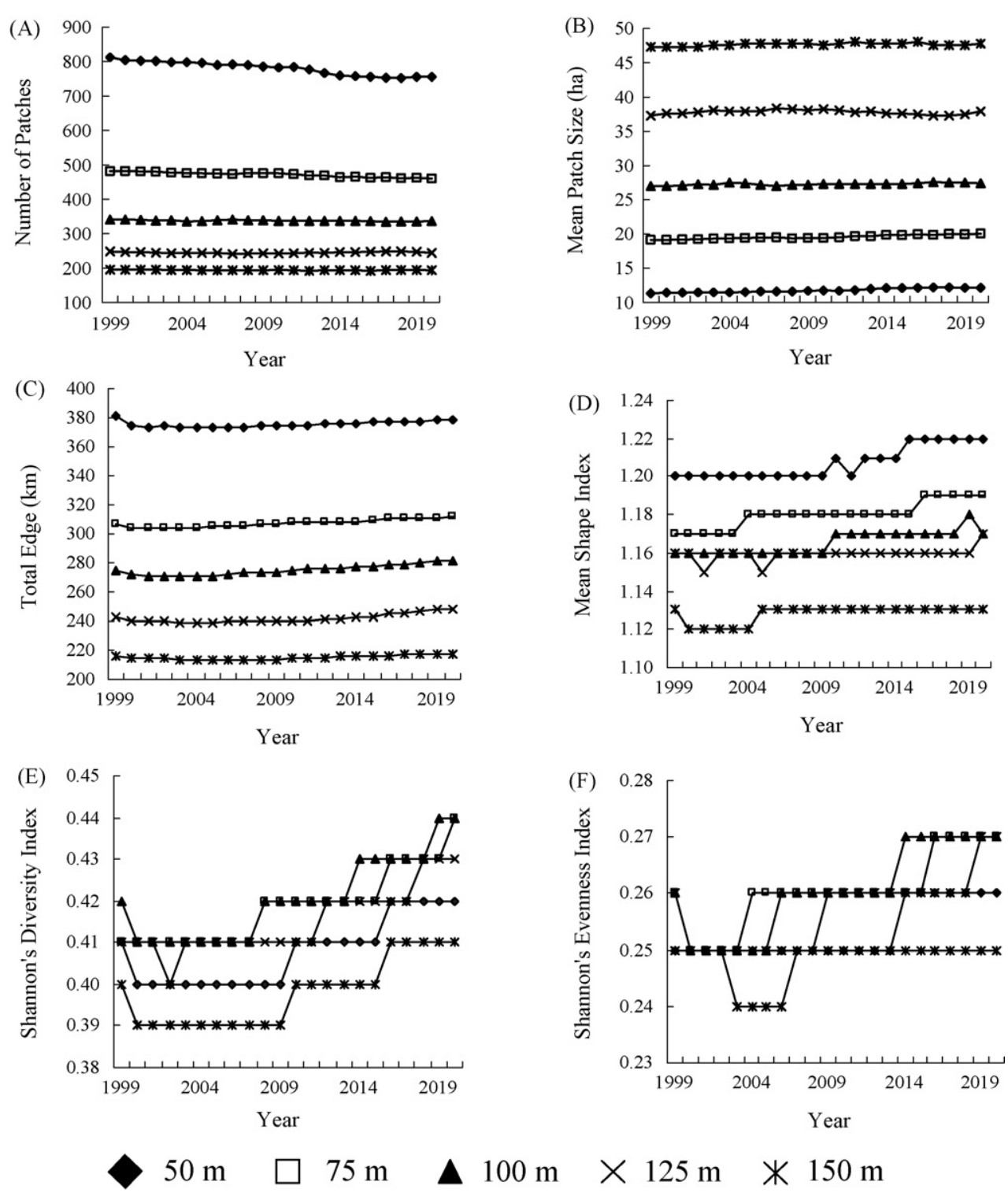

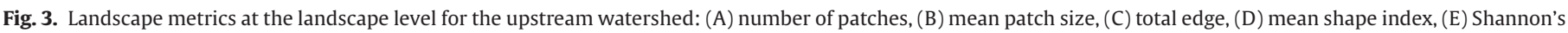
diversity index, and (F) Shannon's evenness index.

the simulated period in both the upstream watershed and the entire watershed (Figs. 3(A), (C), and (D), and 4(A), (C), and (D)). Conversely, the values of MPS increased in both the upstream watershed and the entire watershed at the landscape level when the grain size was increased during the simulated period (Figs. 3(B) and 4(B)). The values of SHDI and SHEI tended to stairstep upward with similar magnitudes during the simulated period when the grain size increased from $50 \mathrm{~m} \times 50 \mathrm{~m}$ to $125 \mathrm{~m} \times 125 \mathrm{~m}$ for the upstream watershed (Fig. 3(E) and (F)). The SHDI and SHEI values also tended to stair-step upward with similar magnitudes during the simulated period when the grain size was increased from $50 \mathrm{~m} \times 50 \mathrm{~m}$ to $150 \mathrm{~m} \times 150 \mathrm{~m}$ for the entire watershed (Fig. 4(E) and $(F))$. To understand the changes in landscape patterns due to land-use changes over the study period, the differences between the baseline year (1999) and subsequent years were considered. Most of the landscape metrics displayed similar values for the baseline year (1999) and the subsequent simulated period for each grain size. For both the upstream watershed and the entire watershed, the values of NP, MPS, and MSI did not differ greatly between the baseline (1999) and the subsequent simulated years
(Figs. 3(A), (B), and (D) and 4(A), (B), and (D)). There was only an obvious declining trend in TE for the grain size $50 \mathrm{~m} \times 50 \mathrm{~m}$ from 1999 to 2000 in the upstream watershed (Fig. 3(C)). However, the TE values showed few differences at other grain sizes for the upstream watershed and the entire watershed (Figs. 3(C) and 4(C)). The SHDI and SHEI values showed consistent stair-step trends for the entire watershed, and the SHEI values also showed a stair-step trend for the upstream watershed (Figs. 3(F), and 4(E) and (F)). In contrast, the SHDI values showed an obvious declining trend from 1999 to 2000 for the upstream watershed (Fig. 3(E)).

The values of global Moran's I for the landscape metrics of subwatersheds in the upstream area were calculated to assess the spatial correlations of land-use patterns in sub-watersheds in 2000, 2010 and 2020. The Moran's I values of SHEI and SHDI for all grain sizes were negative, except for SHDI at grain size $150 \mathrm{~m} \times 150 \mathrm{~m}$ and grain size $50 \mathrm{~m} \times 50 \mathrm{~m}$ in 2000 . However, nearly all the Moran's $I$ values of the other metrics were positive; those that were negative approximated zero. At the landscape level, the gradients of Moran's I values of NP, MPS, TE and MSI for sub-watersheds in the upstream area changed to the reverse direction when the grain size 

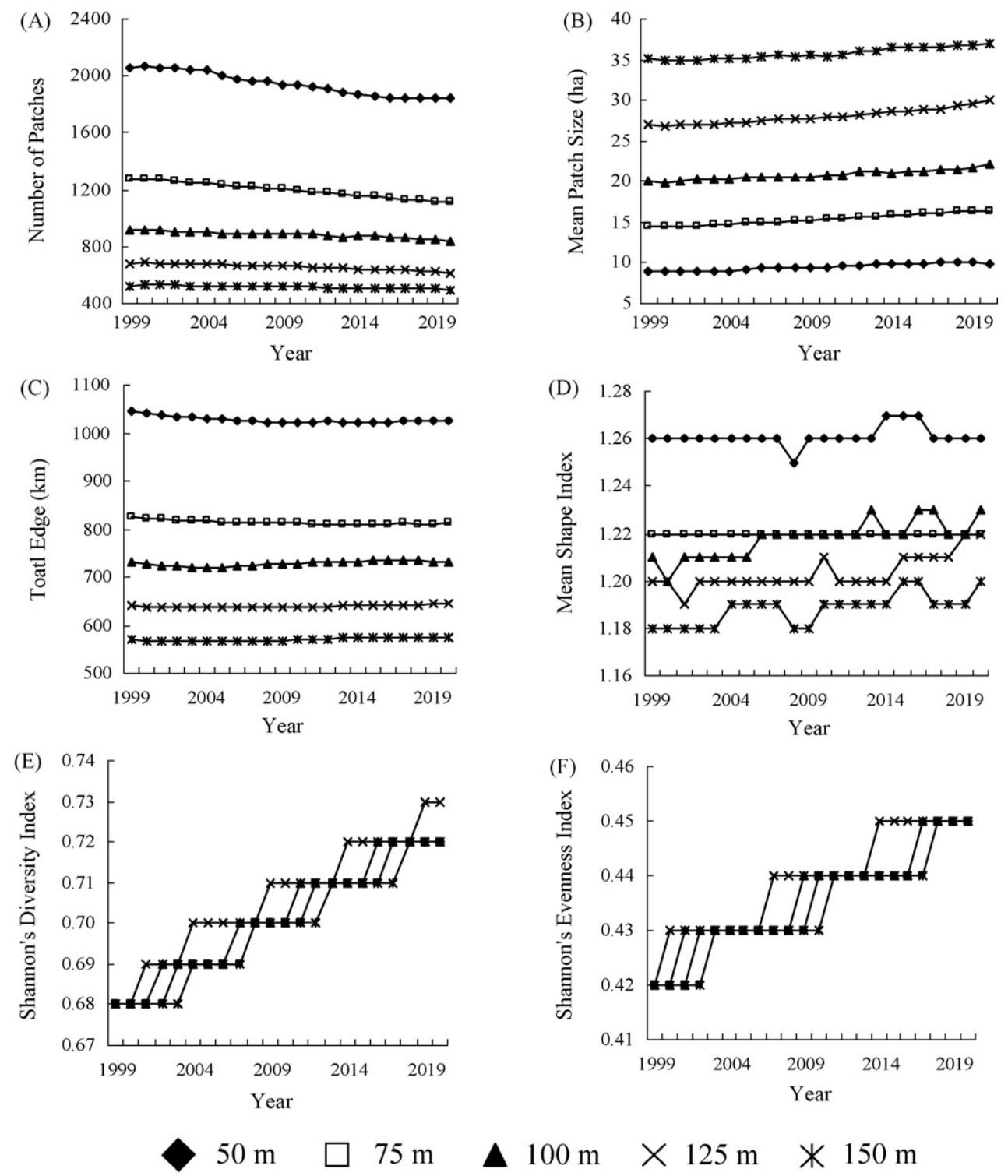

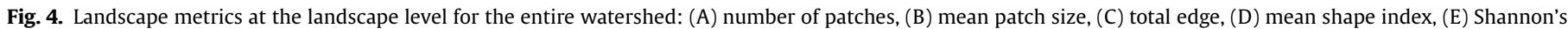
diversity index, and (F) Shannon's evenness index.

$100 \mathrm{~m} \times 100 \mathrm{~m}$ was used in the planning strategy for 2000,2010 , and 2020 (Fig. 5(A)-(D)), except for the gradient of Moran's I for TE in 2020. Moreover, the gradients of Moran's I values of SHDI of subwatersheds in the upstream area changed to the reverse direction when the grain size $125 \mathrm{~m} \times 125 \mathrm{~m}$ was used in the planning strategy for 2000, 2010, and 2020 (Fig. 5(E)). The gradient of Moran's $I$ value for SHEI of sub-watersheds in the upstream area exhibited no obvious tendency when the grain size changed for 2000, 2010, and 2020 (Fig. 5(F)).

\subsection{Simulated hydrological components for changing scales}

In the study period, the built-up areas increased to match the demand while forest, agriculture land and grassland decreased. The increase in built-up land was about 100 ha during the period 1999-2020. The annual runoff, which increased by about $1.5 \%$, was affected significantly by the change in built-up land. Furthermore, both infiltration and groundwater discharge decreased. However, evapotranspiration, caused by the substitution of built-up land for forest land, also decreased. It can be assumed that evapotranspira- tion was as zero in built-up areas. The combined effect of these two factors was groundwater discharge decreased (Fig. 6). The change in the stream flow over the years was close to that of surface runoff. The increasing trends of these two hydrological components were similar, which suggests that surface runoff is one of the main components of the stream flow in the study area.

Simulated groundwater discharge decreased when the grain size applied in land-use simulations increased from $50 \mathrm{~m} \times 50 \mathrm{~m}$ to $100 \mathrm{~m} \times 100 \mathrm{~m}$, but increased when the grain size changed from $125 \mathrm{~m} \times 125 \mathrm{~m}$ to $150 \mathrm{~m} \times 150 \mathrm{~m}$ (Fig. 6(A)). Meanwhile, in the landuse planning strategy, the simulated surface runoff increased when the grain size in land-use simulations changed from $50 \mathrm{~m} \times 50 \mathrm{~m}$ to $100 \mathrm{~m} \times 100 \mathrm{~m}$, and declined when the grain size increased from $125 \mathrm{~m} \times 125 \mathrm{~m}$ to $150 \mathrm{~m} \times 150 \mathrm{~m}$ (Fig. 6(B)). Furthermore, both simulated groundwater discharge and surface runoff at various grain sizes during the simulation period exhibited similar tendencies (increase and decrease) and magnitudes. However, the simulated stream flow for each grain size gradually increased from 2000, the first year of the simulation, and tended to increase steadily in subsequent years (Fig. 6(C)). The magnitudes of simulated stream flows 

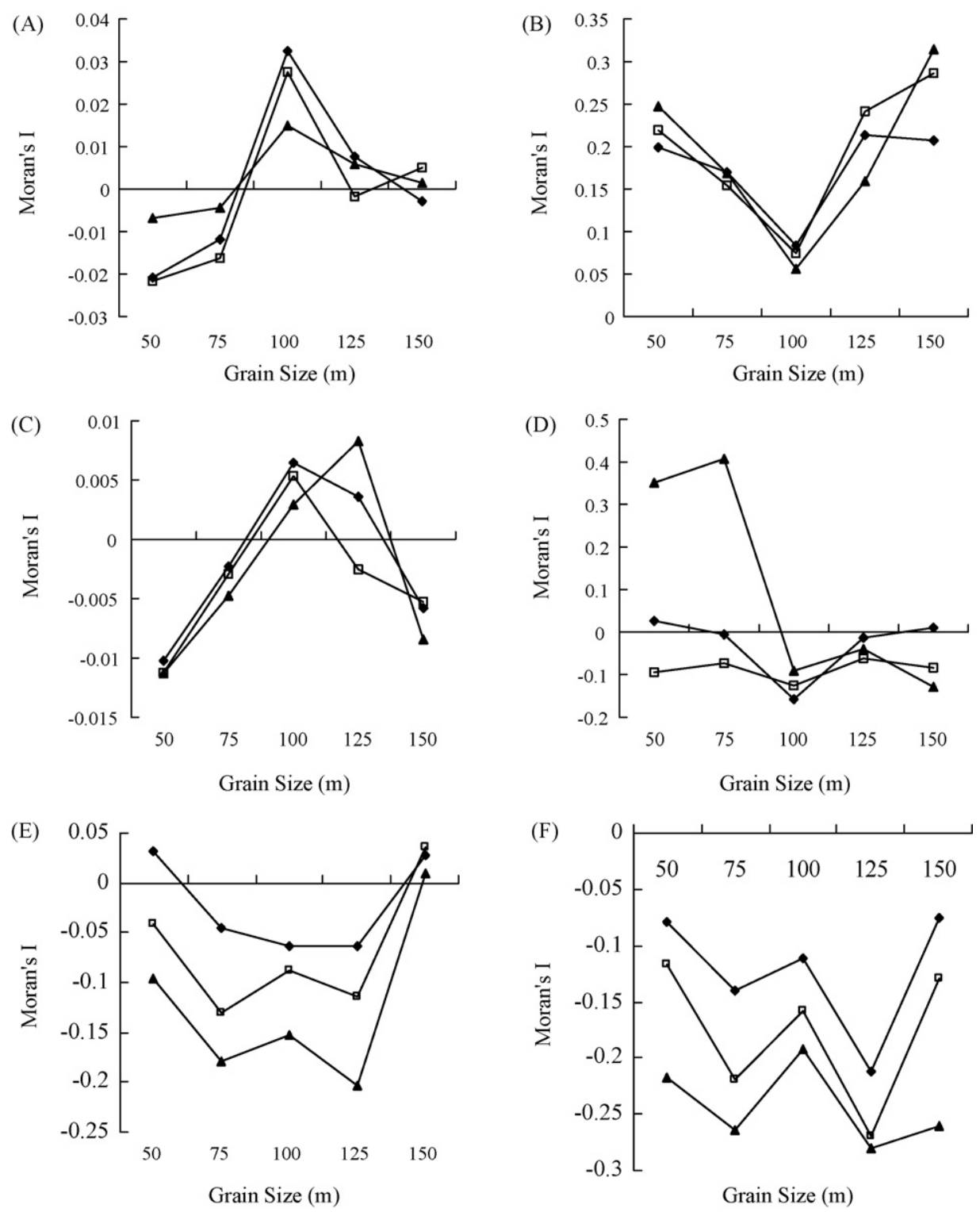

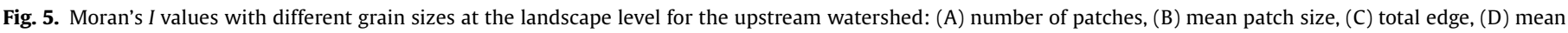
shape index, (E) Shannon's diversity index, and (F) Shannon's evenness index.

for each grain size differed significantly in the upstream watershed, particularly for grain sizes of $50 \mathrm{~m} \times 50 \mathrm{~m}$ and $100 \mathrm{~m} \times 100 \mathrm{~m}$ in all land-use scenarios. Furthermore, the simulated stream flows for a fine grain size increased more rapidly and tended to stabilize earlier than those for other grain sizes, except for a grain size $100 \mathrm{~m} \times 100 \mathrm{~m}$ (Fig. 6(C)).

Compared to the baseline (1999), the simulated groundwater discharge for all grain sizes declined towards the end of the study period. The decreasing rates of groundwater discharge were $-0.94 \%,-1.00 \%,-0.94 \%,-0.96 \%$, and $-0.77 \%$, respectively, for grain sizes $50 \mathrm{~m} \times 50 \mathrm{~m}, 75 \mathrm{~m} \times 75 \mathrm{~m}, 100 \mathrm{~m} \times 100 \mathrm{~m}, 125 \mathrm{~m} \times 125 \mathrm{~m}$, and $150 \mathrm{~m} \times 150 \mathrm{~m}$. Compared to the baseline (1999), both the simulated surface runoff and the stream flow for all grain sizes increased towards the end of the study period. For the simulated surface runoff with grain sizes $50 \mathrm{~m} \times 50 \mathrm{~m}$ to $150 \mathrm{~m} \times 150 \mathrm{~m}$, the increasing rates of surface runoff were $1.43 \%, 1.49 \%, 1.37 \%, 1.45 \%$, and $0.89 \%$, respectively. For the simulated stream flow with grain sizes of $50 \mathrm{~m} \times 50 \mathrm{~m}$ to $150 \mathrm{~m} \times 150 \mathrm{~m}$, the increasing rates of stream flow were $0.25 \%, 0.25 \%, 0.23 \%, 0.25 \%$, and $0.06 \%$, respectively. These simulated hydrological components exhibited similar rates of increase/decrease for different grain sizes, except for the grain size $150 \mathrm{~m} \times 150 \mathrm{~m}$. Moreover, for all hydrological components, the differences between the baseline and the final year of the study were least obvious for the grain size $150 \mathrm{~m} \times 150 \mathrm{~m}$. This result seems to correspond to the properties of land-use changes shown in Fig. 2. The maximum area of forest land and agriculture land occurred at grain size $150 \mathrm{~m} \times 150 \mathrm{~m}$.

Global Moran's I values of the hydrological components of subwatersheds in the upstream area were calculated to assess the spatial correlations of the components of the sub-watersheds. The Moran's I values of the hydrological components were all negative, except for the stream flow at grain size $125 \mathrm{~m} \times 125 \mathrm{~m}$ in 2000 and 2010, and grain size $150 \mathrm{~m} \times 150 \mathrm{~m}$ in 2000 (Fig. 7). The gradients of those values changed to the reverse direction when the grain 

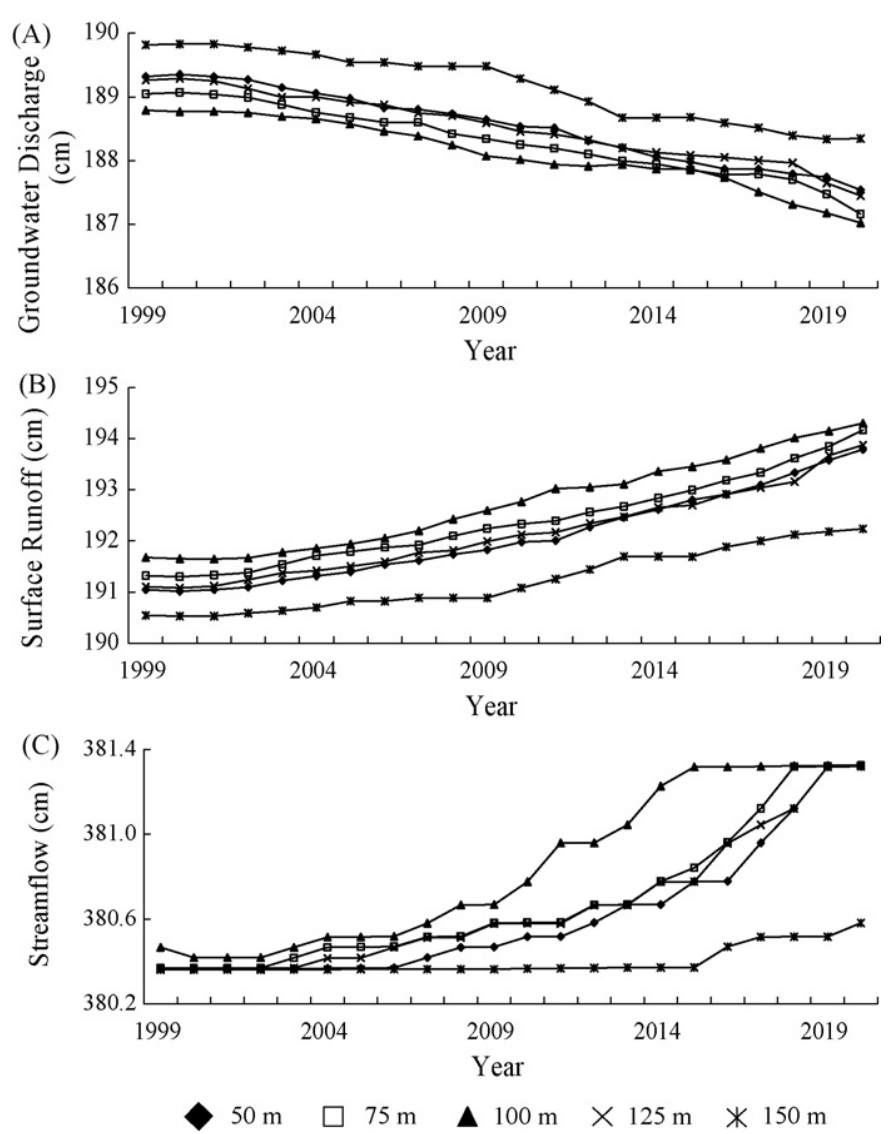

Fig. 6. Cumulative changes of (A) groundwater discharge, (B) surface runoff, and (C) stream flow in the upstream watershed.

size was $100 \mathrm{~m} \times 100 \mathrm{~m}$ in 2000, 2010, and 2020 (Fig. 7), except for groundwater discharges in 2020. Moreover, the tendency and magnitude of Moran's I values of hydrological components of subwatersheds in the upstream area were different for the simulated years 2000, 2010, and 2020 (Fig. 7).

\section{Discussion}

\subsection{Effects of changing the grain size on land-use driving factors}

The effect of changes of scale on simulation results is often hard to detect (Farina, 2000). As variables change with scales, new patterns and processes may emerge, and controlling factors may shift, even for the same phenomena ( $\mathrm{Wu}$ and $\mathrm{Li}, 2006$ ). Observations made at fine scales may miss important patterns and processes operating on broader scales (Wu and Li, 2006). Conversely, broadscale observations may not have enough detail to understand the fine-scale dynamics ( $\mathrm{Wu}$ and $\mathrm{Li}, 2006$ ). However, fine-scale data for study watersheds may not always be available. In this study, the logistic regression results indicate that land-use is usually determined by socio-economic factors, suggesting that urbanization affects land-use patterns in the study watershed. Logistic regression indicates that biophysical features are incorporated as potential benefits that are experienced via a particular type of land-use in a certain location (Verburg and Veldkamp, 2004).

Changing the resolution influences the composition of the variables and the regression coefficients of land-use regression models significantly (de Koning et al., 1998; Verburg et al., 1999). However, Kok and Veldkamp (2001) argued that, although the explanatory power increases, coarsening the spatial resolution does not influ-
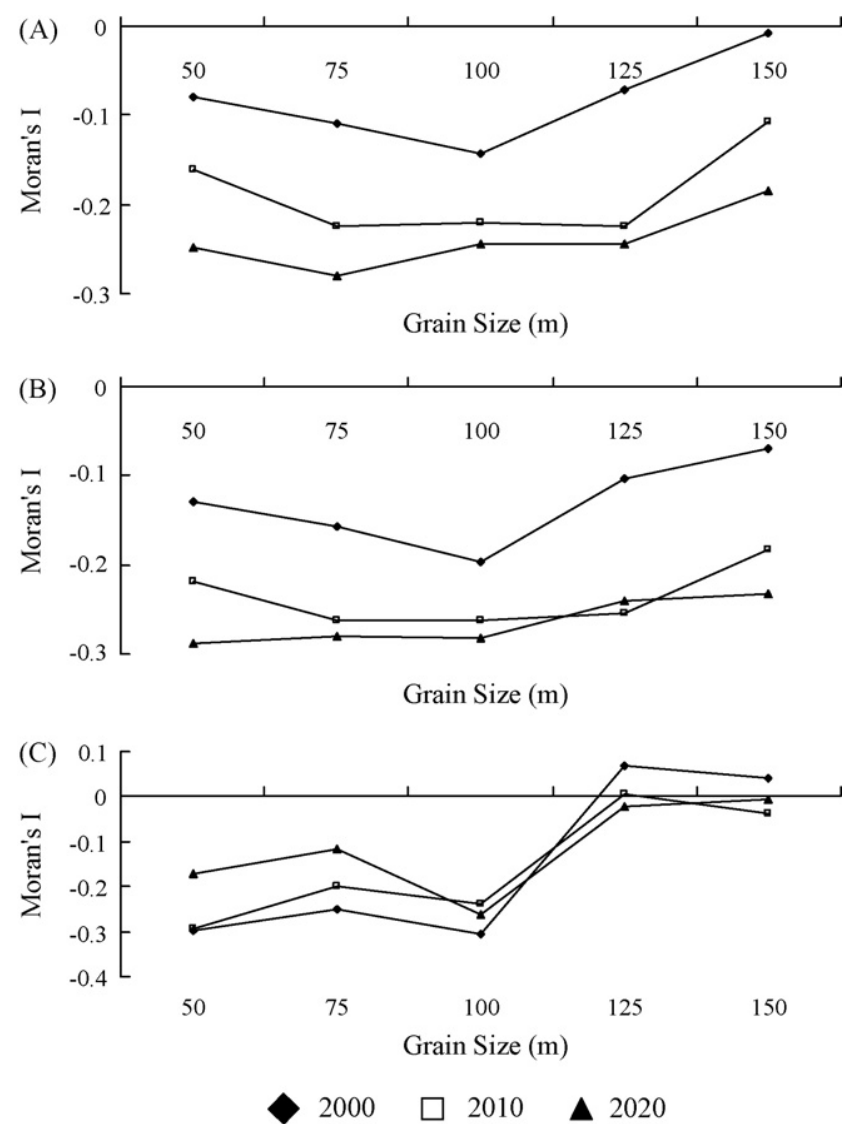

Fig. 7. Moran's $I$ values for different grain sizes at the landscape level for the upstream watershed: (A) groundwater discharge, (B) surface runoff, and (C) stream flow.

ence the composition of the set of land-use determining factors significantly. It has been shown that increased spatial resolution can improve or degrade a model's performance (Ciret and HendersonSellers, 1989). In this study, the ROC values for simulating all types of land-use in various grain sizes were $>0.73$. In fact, the values were very similar for each land-use type, implying that land-use patterns could be reasonably explained by the driving factors of the logistic regression models when the grain size was changed in the cases studied (Table 1). There were significant changes to the composition of the variables and the regression coefficients for land-use logistic regression models when the grain size was more than twice the finest grain size, particularly for built-up areas (Table 1). Logistic regression showed that altering the grain size had various impacts on the composition of the variables in the regression models for land-use patterns with various spatial characteristics, such as the configuration and composition of land-use.

\subsection{Effects of changing scales on land-use patterns}

The different processes that shape land-use patterns can be observed as the variables change with scales (Jantz and Goetz, 2005). Information may be available at a variety of scales and it may be necessary to extrapolate information from one scale to another (Leitão et al., 2006). The scale of the represented land-use data can influence the quantification of land-use patterns and a model's ability to replicate spatial patterns (Jenerette and $\mathrm{Wu}, 2001$; Jantz and Goetz, 2005). The metrics are useful for assessing scale effects on land-use patterns. For instance, Turner (1989) reported that the diversity index decreased linearly with increases in the logarithmic 
grain size. $\mathrm{Wu}$ (2004) reported that, as the size of an area increased, the MPS changed much less than when the grain size changed. In this study, NP, MPS, TE and MSI responded consistently to changes in grain size in each simulated year. SHDI and SHEI presented stairstep responses during the simulated period when the grain size changed. The stair-step responses are similar to the results reported by Turner (1989) and $\mathrm{Wu}$ (2004), which showed that the apparent proportion of the landscape with different types of cover changes with the grain size (Turner, 1989). Moreover, the spatial arrangement of the land cover also influences the rate at which land cover types disappear (Turner, 1989). Comparison of landscape metrics between the baseline year and the final year of the study can help us understand changes in landscape patterns as well as land-use. In this study, the differences in the landscape metrics of the entire watershed between the baseline, 1999, and the final study year, 2020, were all less than 10\%, except for NP and MPS.

The annual mean values of NP, TE, and MSI consistently exhibited a power relation to the grain size during the simulated period in both the upstream and the entire watershed area (Figs. 8(A), (C), and (D), and 9(A), (C), and (D)). The annual mean values of MPS exhibited a linear relation to the grain size in both the entire watershed and the upstream area of the watershed (Figs. 8(B) and 9(B)). The landscape metric-scaling relation results for the simulated period (multiple time-scales) presented a metricscaling relation similar to the results reported by $\mathrm{Wu}$ (2004). The annual mean values of SHDI and SHEI exhibited polynomial relations with the grain size (Figs. 8(E) and (F), and $9(\mathrm{E})$ and $(F)$ ). These results imply that the land-use model used to simulate land-use change processes dominated by biophysical and human drivers, which operate on distinctive spatial and temporal scales, can generate land-use patterns related to the scaling functions (Wu, 2004).

Understanding the role of scale in landscape analysis requires that we distinguish between the scale of observation, where the real landscape is translated into data, and the scale of analysis, where patterns in the data are revealed (Li and Reynolds, 1995; $\mathrm{Li}$ and $\mathrm{Wu}, 2004)$. To adequately quantify the spatial heterogeneity and detect the characteristic scales of a landscape, landscape shape indices should be computed at multiple scales ( $\mathrm{Li}$ and $\mathrm{Wu}$, 2004). In general, at the landscape level, scaling relations are more consistent and predictable with changing grain sizes than with changing extents of the landscape ( $\mathrm{Wu}, 2004)$. In this study, the landscape metrics demonstrated that the composition of the simulated land-use patterns in the watershed changed when the grain size changed. The metrics also showed that the effects of changing the grain size on simulated landscape patterns were significant when the grain size of the watershed was increased. In certain types of landscape data, there is a spatial threshold beyond which scale effects are no longer obvious ( $\mathrm{Qi}$ and Wu, 1996). A scaling threshold may also be understood as a critical scale of a phenomenon, where emergent properties due to nonlinear interactions and spatial heterogeneity come into effect ( $\mathrm{Wu}$ and $\mathrm{Li}, 2006$ ). Moreover, the ecological view and hydrological view of landscapes emphasize the importance of the spatial structure and heterogeneity (Turner, 1989; Schulz et al., 2006; Schröder, 2006). Thus, the development of a set of quantitative, robust, and reproducible methods for the analysis of spatiotemporal patterns that go beyond classical, nonspatial approaches represents a major challenge for model-based analysis of pattern-process interactions in landscape ecology and catchment hydrology (Schröder, 2006).
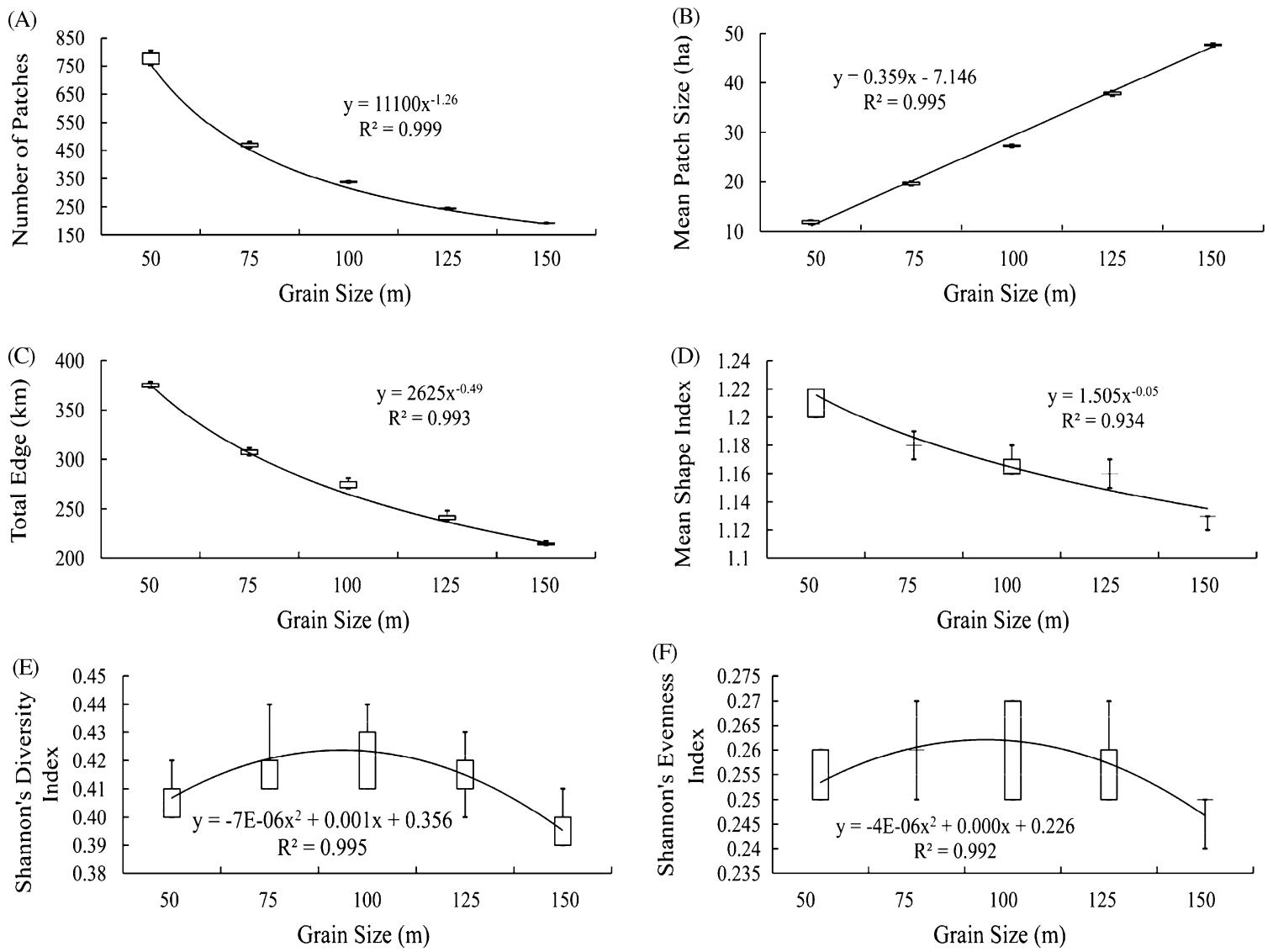

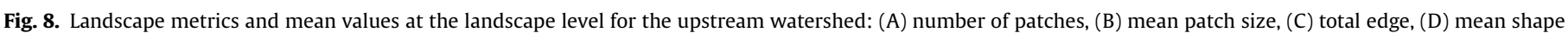
index, (E) Shannon's diversity index, and (F) Shannon's evenness index. 
(A)
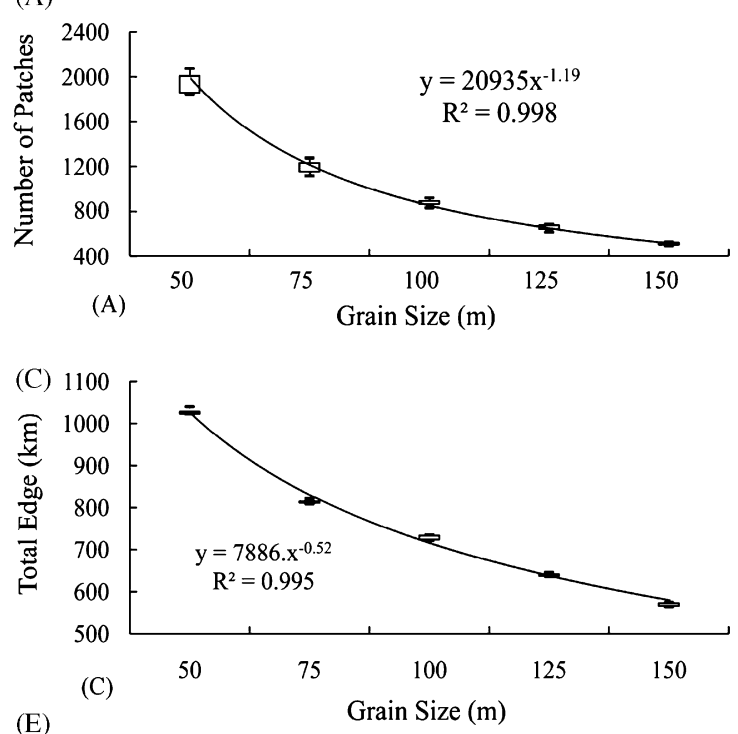

(E)

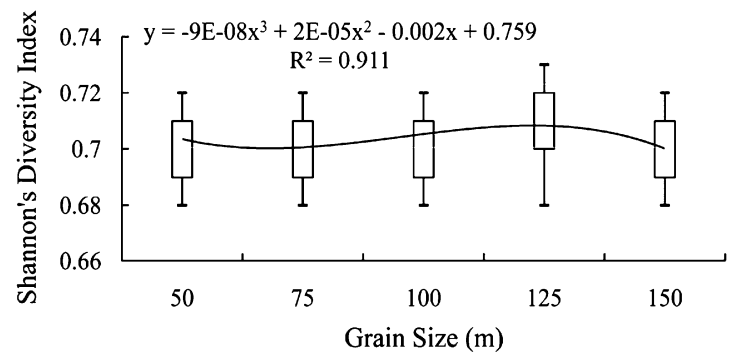

(B)
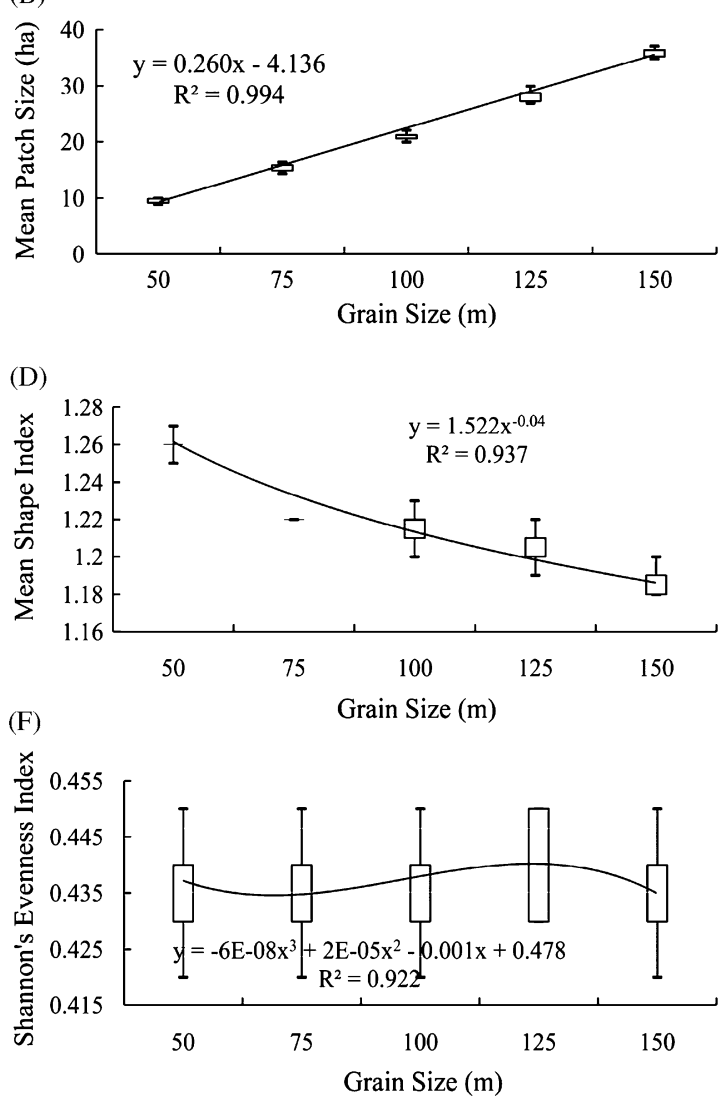

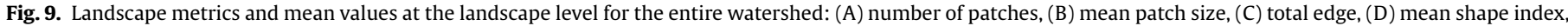
(E) Shannon's diversity index, and (F) Shannon's evenness index.

In this study, at the inflection point (grain size $100 \mathrm{~m} \times 100 \mathrm{~m}$ ), the spatial correlations of land-use patterns in sub-watersheds tended to reverse direction when the grain size was increased from $50 \mathrm{~m} \times 50 \mathrm{~m}$ to $150 \mathrm{~m} \times 150 \mathrm{~m}$ (Figs. 7 and 8 ). The spatial correlations of land-use patterns in sub-watersheds varied over the simulation period. However, the effect of changing the grain size on simulated land-use patterns may also depend on landuse demands and the initial land-use patterns of the watershed, such as the configuration of the watershed's land-use patterns. The spatial correlation results imply that the spatial relations of land-use patterns among sub-watersheds in the upstream area changed gradually when the grain size changed in the simulated period. The grain size threshold for changing the spatial relations of land-use patterns was $100 \mathrm{~m}$ in the sub-watershed. However, adjacent sub-watersheds had almost the same number of patches when the grain size was $100 \mathrm{~m}$, but at that same scale, adjacent sub-watersheds were least similar in terms of their mean patch sizes. This phenomenon may be caused by land-use spatial compositions and the configuration of different sub-watersheds in various scales. When grain sizes changed, the spatial arrangement of landuse also changed. As a result, the effect of scales on spatial land-use patterns may be quite different when the heterogeneity and complexity levels of watershed land-use vary. Moreover, the relation between grain sizes and the sizes of sub-watersheds may also account for differences in the landscape metrics of neighboring sub-watersheds. For instance, the smallest sub-watershed, number 13 , is much smaller than the adjacent sub-watersheds (Fig. 1(C)); thus, less spatial correlation can be expected. Take watershed 2 as another example. It is larger than the other sub-watersheds
(Fig. 1(C)), so it is also expected to have less spatial correlation with adjacent sub-watersheds.

\subsection{Effects of changing scales on hydrology when simulating land-use}

Land-use change models are frequently used to determine the impact of land cover on biophysical processes (Veldkamp and Lambin, 2001), such as a watershed's hydrology. The composition and spatial configuration of sub-watersheds strongly influence hydrological connectivity and control the catchment response (Schröder, 2006). Hydrologists have investigated the relationship between a model's scale and the scales of individual processes involved in the catchment area (Vázquez et al., 2002). Bormann (2006) concluded that a meaningful aggregation of data should, in the first instance, try to preserve the area percentages of different land-use classes, because land-use is the most important information required by a water flux model. The decision about what resolution of data would be sufficient for specific applications of the model has to be made on a case-by-case basis (Bormann, 2006). The built-up area, which can be taken as impervious land, increased in the study period; as a result, the simulated surface water runoff increased. Surface runoff was affected directly by the area of built-up land. Forest land, which can be considered a water conservation area, decreased because of the demand for built-up land; hence, the simulated groundwater discharge decreased.

In this study, the global Moran's $I$ values of the hydrological components and the landscape metrics, SHDI and SHEI were 

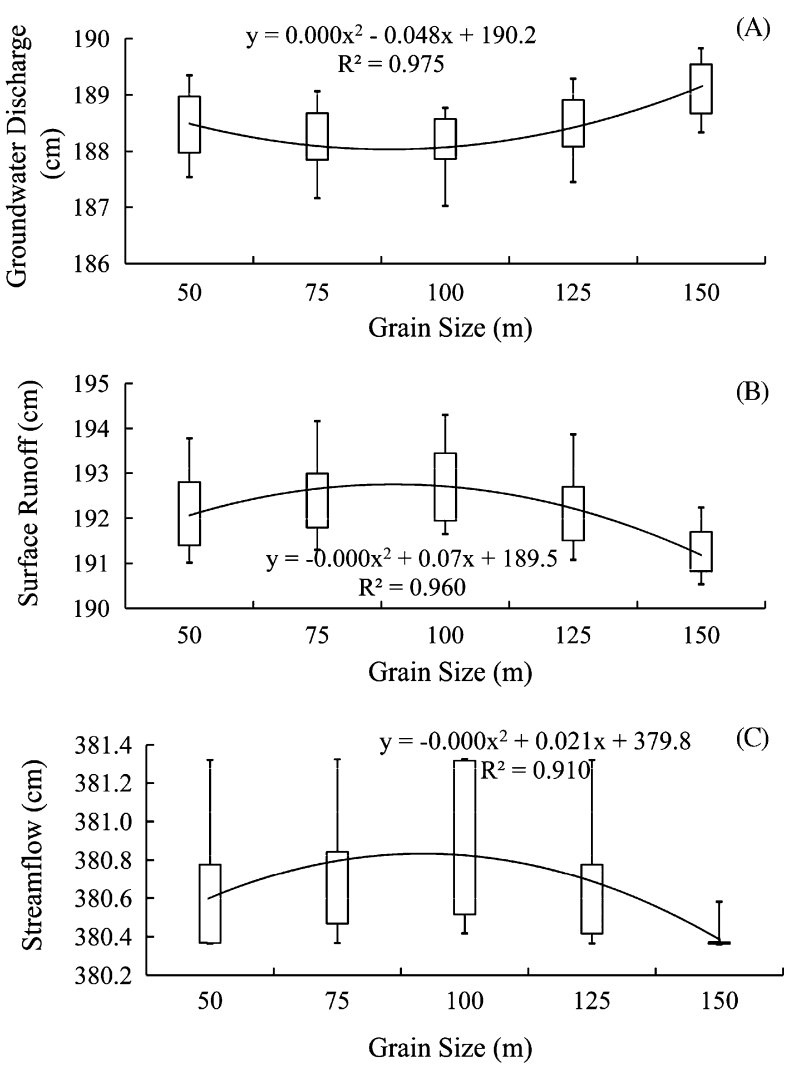

Fig. 10. (A) groundwater discharge, (B) surface runoff, and (C) stream flow and the mean values of different grain sizes in the upstream watershed from 2000 to 2020 .

negative, but the values of the other metrics were positive. This suggests that these two metrics and the hydrological components had similar spatial autocorrelation characteristics (Figs. 5 and 7). The annual mean values of groundwater discharge, surface runoff, and stream flow exhibited polynomial relations with the grain size (Fig. 10(A)-(C)). Moreover, surface runoff, stream flow, SHDI and SHEI exhibited the same type of concave polynomial relations to the grain size, which showed that hydrology depended on the simulated land-use patterns. As Eqs. (4) and (5) show, SHDI and SHEI take land-use ratios into account, and the results reflect the trend of land-use changes. Pearson's correlation coefficients between the surface runoff and SHDI/SHEI for all five grain sizes were 0.92 and 0.88 , respectively, and they correlated significantly at the 0.01 probability level. In addition, Pearson's correlation coefficients between the stream flow and SHDI/SHEI for all five grain sizes were 0.85 and 0.86 , respectively, and they too correlated significantly at the 0.01 probability level (Figs. 7 and 9). Similarly, Pearson's correlation coefficients between the surface runoff and MPS, TE, and MSI for five grain sizes were $-0.32,0.26$, and 0.44 , respectively, revealing a significant correlation at the 0.01 probability level. Meanwhile, Pearson's correlation coefficient between the stream flow and MPS for all five grain sizes was -0.23 , and it correlated significantly at the 0.05 probability level. Finally, Pearson's correlation coefficient between the stream flow and MSI for all five grain sizes was 0.36 , and it correlated significantly at the 0.01 probability level. Groundwater discharge exhibited a convex polynomial relation to the grain size. There was also a correlation between groundwater discharge and some landscape metrics: Pearson's correlation coefficients between groundwater discharge and MPS, TE, MSI, SHDI, and SHEI for all five grain sizes were $0.35,-0.29,-0.47,-0.92$, and -0.85 , respectively, revealing a strong correlation at the 0.01 probability level (Figs. 8 and 10). The polynomial relations could be influenced by the proportion and diversity of land-use patterns, which varied with the grain size. Moreover, the changes in land cover types are not necessarily unidirectional through all aggregations (Turner, 1989).

The simulation results of hydrological modeling based on simulated land-use patterns also indicated that the hydrological components (stream flow, surface runoff and groundwater discharge), especially stream flow, were affected by all grain sizes but to different extents. Additionally, changing the grain size in landuse modeling from $50 \mathrm{~m} \times 50 \mathrm{~m}$ to $125 \mathrm{~m} \times 125 \mathrm{~m}$ did not change the simulated hydrological components significantly, particularly the groundwater discharge and surface runoff in the watershed. The hydrological effects of changes in land cover may be difficult to discern in the case of large-scale basins $\left(>100 \mathrm{~km}^{2}\right)$ (Costa et al., 2003). Bormann (2006) reported that the spatial structure (proportion) of land-use patterns did not have a significant impact on the regularity of the mean annual water flow in simulations based on the grid size aggregation in a large-scale catchment area. In this study, the spatial correlations of hydrological components of the sub-watersheds did not change significantly when the grain size increased from $50 \mathrm{~m} \times 50 \mathrm{~m}$ to $100 \mathrm{~m} \times 100 \mathrm{~m}$. The spatial correlations of simulated hydrology related to those of land-use metrics, which implies that hydrological components had the same reflection point $(100 \mathrm{~m})$ as land-use patterns in the sub-watershed. The results of hydrological analysis also demonstrate that a threshold of reasonable data aggregation can be reached (Bormann, 2006).

\section{Conclusion}

This study integrated an empirical land-use change model, landscape metrics, and a hydrological model to simulate and evaluate future land-use patterns and hydrological processes under a given land-use strategy with different grain sizes and extents in a watershed. Only five grain sizes were used because when the grain size increased beyond $150 \times 150 \mathrm{~m}$ (i.e., to $175 \mathrm{~m} \times 175 \mathrm{~m}$ ), the land-use model could not converge to fit land-use demands. The watershed and sub-watersheds were studied because natural watershed boundaries were used. The land-use change model provided land-use scenarios for land-use pattern analysis and hydrological modeling, which were used to assess land-use strategies and scale effects. The landscape metrics fully represented the simulated land-use patterns and indicated that the effects of changing the grain size on simulated land-use patterns were significant when the grain size reached a particular value. Similarly, simulated hydrological components also changed significantly when the grain size for land-use modeling increased to various specific values in the watershed and sub-watershed scales. The thresholds for the grain size in various extents (watershed and sub-watershed) for simulating both land-use patterns and hydrology can be derived by the proposed approach. Moreover, the relations of land-use patterns and hydrology with the grain size in some simulated hydrological components and land-use patterns represented similar scale-relation functions. This implies that the effects of the grain size are similar in certain simulated land-use patterns and hydrology, and they can be determined by using the proposed method to assess watershed land-use planning strategies. Scaling practices always have a degree of uncertainty because of spatial heterogeneity, nonlinearity, data inadequacy, and problems with scaling techniques (Wu and Hobbs, 2006). The goal of uncertainty analysis is to identify the various sources of uncertainty and quantify its effect on the scaling results (Wu and Hobbs, 2006). In future scaling studies, the issue of uncertainty analysis will be addressed. 


\section{Acknowledgments}

The authors would like to thank the National Science Council of the Republic of China, Taiwan, for financially supporting this research under contract nos. NSC94-2621-Z-002-031 and NSC952621-Z-002-005. The author would also like to appreciate Dr. Verburg and the CLUE-S group for providing the CLUE-S model.

\section{References}

Bormann, H., 2006. Impact of spatial data resolution on simulated catchment water balance and model performance of the multi-scale TOPLATS. Hydrol. Earth Syst. Sci. 10, 165-179.

Ciret, C., Henderson-Sellers, A., 1989. Sensitivity of ecosystem models to the spatial resolution of the NCAR community climate model CCM2. Clim. Dynam. 14, 409-429.

Corry, R.C., Nassauer, J.I., 2005. Limitations of using landscape pattern indices to evaluate the ecological consequences of alternative plans and designs. Landscape Urban Plann. 72, 265-280.

Costa, M.H., Botta, A., Cardille, J.A., 2003. Effects of large-scale changes in land cover on discharge of the Tocantins River. Southeastern Amazonia 283, 206-217.

de Koning, G.H.J., Veldkamp, A., Fresco, L.O., 1998. Land-use in Ecuador: a statistical analysis at different aggregation levels. Agric. Ecosys. Environ. 70, 231-247.

Eckhardt, K., Breuer, L., Frede, H.G., 2003. Parameter uncertainty and the significance of simulated land-use change effects. J. Hydrol. 273, 164-176.

Elkie, P.C., Rempel, R.S., Carr, A.P., 1999. Patch Analyst user manual: a tool for quantifying landscape structure. NWST Technical Manual TM-002. NWST, Ontario.

Farina, A., 2000. Principles and Methods in Landscape Ecology. Kluwer Academic Publishers, Dordrecht, The Netherlands, p. 235.

Haith, D.A., Shoemaker, I.L., 1987. Generalized watershed loading functions for stream flow nutrients. Water Resourc. Bull. 107, 121-137.

Haverkamp, S., Fohrer, N., Frede, H.G., 2005. Assessment of the effect of land-use patterns on hydrologic landscape functions: a comprehensive GIS-based tool to minimize model uncertainty resulting from spatial aggregation. Hydrol. Process. 19, 715-727.

Howarth, R.W., Fruci, J.R., Sherman, D., 1991. Input of sediment and carbon to an estuarine ecosystem: influence of land-use. Ecol. Appl. 1, 27-39.

Jantz, C.A., Goetz, S.J., 2005. Analysis of scale dependencies in an urban land-use change model. Int. J. Geograph. Inform. Sci. 19, 217-241.

Jenerette, D.G., Wu, J., 2001. Analysis and simulation of land-use change in the central Arizona-Pheoenix region, USA. Landscape Ecol. 16, 611-626.

Jongman, R.H.G., 1999. Landscape ecology: landscape ecology in land-use planning. In: Wiens, J.A., Moss, M.R. (Eds.), International Association for Landscape Ecology. Guelph, Ontario, pp. 112-118.

Kok, K., Veldkamp, A., 2001. Evaluating impact of spatial scales on land-use pattern analysis in Central America. Agric. Ecosys. Environ. 85, 205-221.

Legendre, P., 1993. Spatial autocorrelation: trouble or new paradigm? Ecology 74, 1659-1673.

Legendre, P., Legendre, L., 1998. Numerical Ecology. Developments in Environmental Modelling, vol. 20. Elsevier, Amsterdam, p. 853.

Leitão, A.B., Ahern, J., 2002. Applying landscape ecological concepts and metrics in sustainable landscape planning. Landscape Urban Plann. 59, 65-93.

Leitão, A.B., Miller, J., Ahern, J., McGarigal, K., 2006. Measuring Landscapes: A Planner's Handbook. Island Press, Washington D.C., USA.

Li, H., Wu, J., 2004. Use and misuse of landscape indices. Landscape Ecol. 19, 389-399.

Li, H., Reynolds, J.F., 1995. On definition and quantification of heterogeneity. Okios 73, 280-284.

Lin, Y.P., Chang, T.K., Wu, C.F., Chian, D.G., Lin, S.H., 2006. Assessing impacts of typhoons and the ChiChi earthquake on Chenyuland watershed landscape patterns in Central Taiwan. Environ. Manage. 38, 108-125.

Lin, Y.P., Hong, N.M., Wu, P.J., Wu, C.F., Verburg, P.H., 2007. Impacts of land-use change scenarios on hydrology and land-use patterns in the $\mathrm{Wu}$-Tu watershed in Northern Taiwan. Landscape Urban Plann. 80, 111-126.

McGarigal, K., 2002. Landscape pattern metrics. In: El-Shaarawi, A.H., Piegorsch, W.W.(Eds.), Encyclopedia of Environmetrics, vol. 2. John Wiley and Sons, Sussex, England, pp. 1135-1142.

McGarigal, K., Marks, B.J., 1995. FRAGSTATS: spatial pattern analysis program for quantifying landscape structure. USDS For. Sev. Gen. Tec. Rep. PNW-351.
Meentemeyer, V., Box, E.O., 1987. Scale effects in landscape studies. In: Turner, M.G (Ed.), Landscape Heterogeneity and Distribution. Springer-Verlag, New York, pp. 15-34.

Moran, P.A.P., 1950. Notes on continuous stochastic phenomena. Biometrika 37, 17-23.

O’Neill, R.V., Hunsaker, C.T., Timmins, S.P., Jackson, B.L., Jones, K.B., Riitters, K.H., Wickham, D.J., 1996. Scale problems in reporting landscape pattern at the regional scale. Landscape Ecol. 11, 169-180.

Overmars, K.P., de Koning, G.H., Veldkamp, A., 2003. Spatial autocorrelation in multiscale land-use models. Ecol. Model. 164, 257-270.

Overmars, K.P., Verburg, P.H., 2005. Analysis of land-use drivers at the watershed and household level: linking two paradigms at the Philippine forest fringe. Int. J. Geograph. Inform. Sci. 19, 125-152.

Price, S.J., Marks, D.R., Howe, R.W., Hanowski, J.M., Niemi, G.J., 2005. The importance of spatial scale for conservation and assessment of anuran populations in coastal wetlands of the western Great Lakes, USA. Landscape Ecol. 20, 441-454.

Qi, Y., Wu, J., 1996. Effects of changing scale on the results of landscape pattern analysis using spatial autocorrelation indices. Landscape Ecol. 11, 39-50.

Schröder, B., 2006. Pattern, process and function in landscape ecology and catchment hydrology-how can quantitative landscape ecology support predictions in ungauged basins? Hydrol. Earth Syst. Sci. 10, 967-979.

Schulz, K., Seppelt, R., Zehe, E., Vogel, H., Attinger, S., 2006. The importance of structure and its dynamics in advancing hydrological sciences. Water Resourc. Res. 42, W03S03, doi:10.1029/2005WR004301.

Sivapalan, M., 2005. Pattern, process and function: elements of a unified theory of hydrology at the catchment scale. Encyclop. Hydrol. Sci..

Tung, C.P., 2001. Climate change impacts on water resources of the Tesngwen Creek watershed in Taiwan. J. Am. Water Resourc. Assoc. 37, 167-176.

Turner, M.G., 1989. Landscape ecology: the effect of pattern on process. Ann. Rev. Ecol. Syst. 20, 171-197.

Turner, M.G., 2005. Landscape ecology: what is the state of the science? Ann. Rev Ecol. Syst. 36, 319-344.

Turner, M.G., Gardner, R.H., O'neill, R.V., 2001. Landscape Ecology in Theory and Practice, Pattern and Process. Springer-Verlag, New York.

Vázquez, R.F., Feyen, L., Feyen, J., Refsgaard, J.C., 2002. Effect of grid size on effective parameters and model performance of the MIKE-SHE code. Hydrol. Process. 16, 355-372.

Veldkamp, T., Lambin, E.F., 2001. Editorial: Predicting land-use change. Agric. Ecosys. Environ. 85, 1-6.

Verburg, P.H., de Koning, G.H.J., Veldkamp, A., Bouma, J., 1999. A spatial explicit allocation procedure for modeling the pattern of land-use change based upon actual land-use. Ecol. Model. 116, 45-61.

Verburg, P.H., Veldkamp, A., 2004. Projecting land-use transitions at forest fringes in the Philippines at two spatial scales. Landscape Ecol. 19, 77-98.

Wiens, J.A., 1989. Spatial scaling in ecology. Funct. Ecol. 3, 385-397.

$\mathrm{Wu}, \mathrm{J} ., 2004$. Effects of changing scale on landscape pattern analysis: scaling relations. Landscape Ecol. 19, 125-138.

Wu, J., Hobbs, R., 2006. Key Topics in Landscape Ecology. Cambridge University Press, Cambridge.

Wu, J., Li, H., 2006. Concepts of scale and scaling. In: Wu, J., Jones, K.B., Li, H., Loucks, O.L. (Eds.), Scaling and Uncertainty Analysis in Ecology: Methods and Applications. Springer, Dordrecht, The Netherlands, pp. 3-14.

Wu, J., Shen, W., Sun, W., Tueller, P.T., 2002. Empirical patterns of the effects of changing scale on landscape metrics. Landscape Ecol. 17, 761-782.

Yu-Pin Lin is a faculty member in the Department of Bioenvironmental Systems Engineering at National Taiwan University. He received his Ph.D. degree from the Georgia Institute of Technology in the United States in 1995. Dr. Lin is interested in the application and development of geostatistical methods, quantitative methods in landscape ecology, watershed land-use modeling, optimal monitoring sampling design, and environmental modeling.

Pei-Jung Wu is a graduate student in the Department of Bioenvironmental Systems Engineering at National Taiwan University in Taiwan.

Nien-Ming Hong is an assistant professor of the Department of Environmental Resources Management at the Overseas Chinese Institute of Technology in Taiwan. He holds his doctoral degree from the Department of Bioenvironmental Systems engineering in Taiwan University. He has studied in hydrological process modeling and water resources management. 